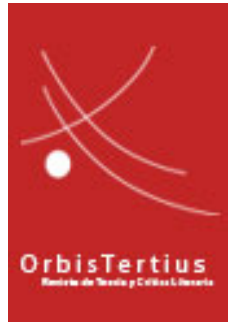

Orbis Tertius, vol. XXIII, nº 28, e100, diciembre 2018. ISSN 1851-7811

Universidad Nacional de La Plata

Facultad de Humanidades y Ciencias de la Educación

Centro de Estudios de Teoría y Crítica Literaria

\title{
Adriana Petra, Intelectuales y cultura comunista. Itinerarios, problemas y debates en la Argentina de posguerra.
}

Buenos Aires, Fondo de Cultura Económica, 2017, Historia, 444 páginas.

\section{Gastón Figueroa}

Cita sugerida: Figueroa, G. (2018). [Revisión del libro Intelectuales y cultura comunista. Itinerarios, problemas y debates en la Argentina de posguerra por Gastón Figueroa]. Orbis Tertius, 23(28), e100. https://doi.org/10.24215/18517811e100

(c) (-) (2) Esta obra está bajo licencia Creative Commons Atribución-NoComercial-CompartirIgual 4.0 Internacional http://creativecommons.org/licenses/by-nc-sa/4.0/deed.es_AR 
Adriana Petra, Intelectuales y cultura comunista. Itinerarios, problemas y debates en la Argentina de posguerra.

Buenos Aires, Fondo de Cultura Económica, 2017, Historia, 444 páginas.

Este libro, reelaboración de la tesis doctoral presentada por Adriana Petra en la Facultad de Humanidades y Ciencias de la Educación de la Universidad Nacional de La Plata en 2013, analiza el complejo vínculo entre los intelectuales comunistas argentinos (comprendiendo, en este sentido, tanto a militantes orgánicos del Partido Comunista Argentino como a simpatizantes o "compañeros de ruta") y el comunismo oficial, encarnado tanto en la Unión Soviética como en sus manifestaciones a nivel nacional e internacional. Aunque centrado en la década del cincuenta (según la autora, un período poco abordado por los estudios acerca de la cuestión), la obra abarca un lapso temporal más amplio, desde la creación del Partido Comunista Argentino en 1918, hasta la ruptura con el partido, por parte de los jóvenes intelectuales vinculados a la revista Pasado y Presente, en la década del sesenta. En este recorrido, también se consideran el anti-fascismo de los años treinta y el ascenso del peronismo en la década siguiente. Más allá de que el libro intenta vincular el derrotero de la intelectualidad comunista argentina con los desarrollos políticos generales, desde una perspectiva cronológica, el análisis se estructura en torno de algunos ejes concretos que dan cuenta de la relativa autonomía entre estos dos campos. Un ejemplo de esto es el tratamiento que le da al período temporal privilegiado por el libro (esto es, la segunda mitad de la década del cuarenta y la década del cincuenta), ordenado en torno a temáticas tales como el anti-imperialismo, el vínculo complejo con el peronismo, el "Movimiento por la Paz" o el itinerario y la obra de Héctor Agosti.

A la hora de definir el concepto de "intelectual", Petra se distancia de la concepción sustancialista que parte de la idea de "trabajador intelectual", incluyendo en la categoría a un amplio espectro de actores vinculados a las llamadas "profesiones liberales" (médicos, abogados y maestros entre otros). Centrándose en la figura del "escritor-intelectual", que abarca tanto al ensayismo como a la literatura en general, el libro analiza ciertas figuras de la cultura comunista argentina con capacidad de intervención pública a partir de sus obras y opiniones. Este recorte parte del papel predominante que ocupa la categoría de "intelectual" en el establecimiento de lineamientos centrales para la política cultural comunista, en experiencias y perspectivas tales como el anti-fascismo, el anti-imperialismo y el movimiento pacifista. También se justifica en el carácter central que ocupa la literatura en el comunismo filo-soviético, no solo en tanto disciplina artística sino también como herramienta pedagógica dirigida la concientización de las masas.

Tal como lo plantea la autora, la obra se inscribe en la tradición de la historia intelectual esbozada por JeanFrançois Sirinelli y por Carlos Altamirano - alejándose de la concepción clásica de la historia de las ideas, focalizada en grandes nombres y textos canónicos-, planteando así una perspectiva más amplia, vinculada a una multiplicidad de contextos, figuras, itinerarios, tradiciones culturales, y redes tanto de sociabilidad como de circulación de ideas. Esta perspectiva se despliega a través del análisis de una diversidad de espacios culturales nacionales e internacionales, incluyendo instituciones, publicaciones periódicas, editoriales y ámbitos de asociación e intercambio tanto con intelectuales afines como ajenos a la órbita partidaria. Al mismo tiempo, el abordaje se ve enriquecido por el uso de una multiplicidad de fuentes, que abarcan tanto el análisis de textos críticos y de documentación institucional, como de publicaciones periodísticas, revistas, legajos policiales, correspondencia privada y diarios personales. 
En relación con lo anterior, cabe aclarar que la obra no elude el análisis de textos canónicos. Muestra de esto es el análisis de Humanismo burgués y humanismo proletario de Aníbal Ponce, o de Echeverría. Nación y cultura y de El mito liberal de Héctor Agosti, entre otros textos relevantes del comunismo argentino. En el caso de su lectura de Echeverría de Agosti, Petra demuestra cómo una concepción liberal de la historia argentina, heredera de las obras de José Ingenieros y de Aníbal Ponce, convive con la recepción hecha por el propio Agosti del pensamiento de Antonio Gramsci (en particular, respecto del proceso de construcción del Estado italiano) y la revalorización del problema de la "nación", reforzada en la cultura comunista mundial a partir del inicio de la Guerra Fría. Esta confluencia, que se da en el marco del vínculo conflictivo establecido entre la intelectualidad comunista argentina y el peronismo y, del incipiente distanciamiento, por parte de Agosti, respecto de la tradición liberal (central en la perspectiva histórica argentina del PCA), da cuenta de la interpenetración entre diferentes discursos y de la convivencia conflictiva entre elementos "residuales" y "emergentes" (en el sentido fijado por Raymond Williams en Marxismo y literatura). Es por ello que, en este caso como en otros, Petra logra distanciarse tanto respecto de una historia de las ideas tradicional, centrada en un análisis esencialista y a-histórico de los discursos, como de un mero historicismo reduccionista, que limita sus perspectivas a un contexto histórico acotado, corriendo el riesgo de desvincularse del análisis de tradiciones y de herencias culturales. Así, la autora logra situar las ideas en un devenir histórico más amplio, demostrando cómo éstas juegan un rol central a la hora de establecer identidades políticas.

El lugar prominente del liberalismo en la constelación ideológica del comunismo argentino, en tanto elemento "residual", echa luz sobre uno de los aspectos centrales del libro en lo referente al desarrollo de la cultura comunista a nivel internacional. La existencia particular de esta herencia cultural en Argentina, que le da al comunismo autóctono rasgos distintivos, se diferencia respecto de las perspectivas que conciben el vínculo entre comunismo soviético y encarnaciones locales desde un punto de vista monolítico y unilateral. Por el contrario, Petra hace hincapié en la necesidad de tener en cuenta las tradiciones y las herencias políticoculturales a nivel nacional, y la ubicación con respecto a éstas por parte del comunismo local. Tales variables, combinadas con las directrices irradiadas desde el centro político-ideológico (en este caso, la URSS) permiten aprehender el perfil particular que la experiencia comunista asumió en Argentina, e intuir las peculiaridades que es necesario considerar también frente a otros contextos nacionales.

El libro se ve atravesado por un eje problemático central: la relación conflictiva entre el campo intelectual y la dinámica particular de la política partidaria. Distanciándose respecto de perspectivas que ven la adhesión de los intelectuales al comunismo como obra de una suerte de fervor "religioso" que los constituye en meras marionetas al servicio de una estructura partidaria jerárquica y autoritaria, Petra los sitúa entre dos dinámicas vinculadas pero relativamente autónomas. La respuesta que deben dar a los mandatos dogmáticos del partido se encuentra tensionada por su pertenencia al campo intelectual, que posee una dinámica propia. Un ejemplo de las problemáticas que puede generar esta tensión es la denominada "crisis Real" ocurrida en 1952: para los intelectuales del partido, este breve intento de acercamiento al gobierno peronista (al cual, a pesar de quitar el mote de "fascismo criollo", siguen oponiéndose en tanto encarnación de un corporativismo autoritario) significa la ruptura con el espacio liberal al cual están vinculados, abandonando instituciones como el CLES (Colegio Libre de Estudios Superiores) y la SADE (Sociedad Argentina de Escritores). El retorno de Victorio Codovila y la expulsión del artífice del affaire, el secretario del partido Juan José Real, devuelve al PCA al bando opositor, y reactiva sus intenciones de vincularse a sectores liberales. Los intelectuales comunistas (que acompañan con recelo este movimiento, justificándolo a partir de su adhesión al anti-imperialismo y la revitalización del concepto de "nación"), quedan desfasados, ya que rompen con un antiguo ámbito de pertenencia, como el espacio liberal, sin poder establecer vínculos duraderos con la intelectualidad peronista. Como compensación ante este aislamiento, apelan a la profesionalización del espacio intelectual comunista. Sin embargo, ese proceso se ve acompañado por el incremento de la vigilancia sobre la aplicación de los lineamientos del zhdanovismo (en una perspectiva que, en 1945, refuerza el establecimiento del realismo socialista como estética oficial del mundo soviético). 
El vínculo conflictivo entre el campo intelectual y la dinámica partidaria puede entreverse también en los procesos de recepción. En referencia al párrafo anterior, el libro muestra cómo la adopción de los lineamientos del zhdanovismo y el realismo socialista no se da de manera lineal ni está exenta de conflictos. Ejemplo de esto son figuras centrales en la cultura comunista, como Raúl González Tuñón o la revista Nueva Gaceta, editada en 1949 y dirigida por Héctor Agosti, de perspectiva claramente "heterodoxa". En otro sentido, la recepción de Gramsci (la cual tiene a Agosti como figura central) y del pensamiento de izquierda italiano en general, a partir de los cincuenta, termina por convertirse en un elemento central para la conformación de la identidad de los jóvenes comunistas agrupados en torno a la revista Pasado y Presente, sector que rompe con el PCA en el marco de un proceso de modernización de las ciencias sociales, de recambio generacional, de revisión de la experiencia peronista, de relectura del marxismo y de ajuste de cuentas con la tradición liberal (dentro de la cual se incluye tanto al Partido Socialista como al Partido Comunista). Tal como señala la autora, aquí el enfoque no está puesto solo en la recepción y apropiación de tal o cual concepto gramsciano, sino más bien en la forma en que esa recepción se transforma en dinamizadora de un espacio intelectual en constante proceso de reacomodación.

La tensión entre el campo intelectual y la dinámica partidaria también ayuda a deconstruir las concepciones que muestran a los intelectuales comunistas como meras marionetas, dispuestas a justificar los lineamientos políticos de Moscú y de sus respectivas encarnaciones a nivel nacional. Petra hace hincapié en el hecho de que el vínculo es beneficioso para ambas partes ya que, a pesar de las contradicciones que puede generar, en los intelectuales comunistas, la defensa del Estado soviético y de concepciones restrictivas tales como el realismo socialista, la participación en el espacio cultural comunista les otorga un ámbito de pertenencia y legitimidad, al mismo tiempo que ofrece ventajas para el ejercicio de la actividad. En el caso argentino, en el cual los intelectuales comunistas — más allá de la órbita del partido-, ocupan un lugar marginal en el ámbito cultural, la participación en espacios tales como el "Movimiento por la Paz" o el anti-fascismo les brinda acceso a una amplia red internacional a través de la cual pueden vincularse con prestigiosas figuras de la cultura a nivel mundial, al mismo tiempo que les facilita un espacio de intercambio, circulación y traducción de sus propias obras, permitiéndoles llegar a lectores de distintas latitudes. En este sentido, podemos decir que las perspectivas y ejes problemáticos planteados por el libro no solo ayudan a abordar el vínculo entre intelectuales y cultura comunista en Argentina, sino que también sientan las bases tanto para estudios focalizados en el establecimiento de redes político-culturales y de circulación de ideas a nivel transnacional (ya sea en escala continental como mundial), como para realizar trabajos de carácter comparativo entre distintas experiencias nacionales. Por otra parte, aunque el análisis esté centrado en Buenos Aires, puede servir como punto de partida para abordar el espacio cultural comunista a nivel nacional (dando cuenta, por ejemplo, de las redes tendidas a nivel interprovincial a partir del anti-fascismo y de la Agrupación de Intelectuales, Artistas, Periodistas y Escritores), sumando así, al rico enfoque del libro, un posible análisis del complejo vínculo entre la capital portuaria y el interior del país.

Uno de los aportes más interesantes del libro se encuentra en la atención especial que presta al mundo editorial relacionado con el PCA. Tal como señala la autora, son escasos los estudios focalizados en el libro político y el trabajo editorial vinculado a organizaciones partidarias, presentándose ésta como un área potencial e ineludible a la hora de encarar futuros análisis de la cultura comunista. Editoriales como Anteo, Lautaro, Futuro o Problemas, entre otras, juegan un importantísimo papel, no solo en la difusión del pensamiento comunista - donde la palabra escrita desempeña un rol pedagógico central一, sino también en la construcción de entramados y redes de difusión que, en el caso argentino, involucran a una gran cantidad de actores; se extienden a lo largo de todo el país, y significan, en muchos casos, una fuente de sustento económico. Incluso la crítica literaria y la historia del arte podrán tener aquí un nuevo punto de partida para repensar la relación entre arte y política en Argentina.

En definitiva, podemos decir que el libro realiza un abordaje enriquecedor sobre el complejo vínculo entre intelectuales y cultura comunista, ofreciendo tanto una perspectiva panorámica, de mediano plazo, como 
así también un análisis profundo y multidimensional sobre problemáticas específicas que rompe con las perspectivas reduccionistas sobre este espacio intelectual, para dar cuenta de las dinámicas peculiares de un entramado conflictivo y en movimiento constante. 